\title{
Post-Stroke Oculomotor Nerve Palsy Treated by Traditional Korean Medicine: Three Case Reports
}

\author{
Yoo-na Lee, Yu-min An, Woo-seok Jang, Kyungmin Baek \\ Dept. of Cardiovascular and Neurologic Diseases of Korean Internal Medicine, \\ Daegu Korean Hospital of Daegu Haany University
}

\section{Post-Stroke Oculomotor Nerve Palsy Treated by Traditional Korean Medicine: Three Case Reports}

\author{
Yoo-na Lee, Yu-min An, Woo-seok Jang, Kyungmin Baek \\ Dept. of Cardiovascular and Neurologic Diseases of Korean Internal Medicine, \\ Daegu Korean Hospital of Daegu Haany University
}

\begin{abstract}
Post-stroke oculomotor nerve palsy occurs more frequently than previously reported, but only a few studies of traditional Korean medicine treatments have been reported. The symptoms are severe and difficult to treat, and current treatments are high-cost, short-lasting, insufficient for shortening the therapeutic period and promoting better recovery, or involve the risk of post-operative over-correction or under-correction. Traditional Korean medicine treatments may be comparatively effective at lower cost and less harmful. Thus, we report three cases of post-stroke oculomotor nerve palsy treated with traditional Korean medicine.
\end{abstract}

Key words: case report, oculomotor nerve palsy, post-stroke, traditional Korean medicine

\section{Introduction}

Oculomotor nerve palsy (ONP) makes up for one third of whole cranial nerve palsies ${ }^{1}$. It may result in ophthalmoplegia, ptosis or pupillary dilation, due to innervation of oculomotor nerve to levator

· 투고일: 2019.10.21, 심사일: 2019.12.19, 게재확정일: 2019.12.27

- Corresponding author: Kyungmin Baek Dept. of Cardiovascular and Neurologic Diseases of Korean Internal Medicine, Daegu Korean Hospital of Daegu Haany University, 136 Shincheon-dong-ro, Suseong-gu, Daegu, South Korea TEL: 053-770-2118 FAX: 053-770-2055 E-mail: kmb1004@hanmail.net palpebrae (LP), sphincter pupillae (SP), ciliary muscle, superior rectus (SR), inferior rectus (IR), medial rectus (MR) and inferior oblique $(\mathrm{IO})^{2}$.

While several diseases are considered to be the causes of $\mathrm{ONP}^{3}$, there are strong likelihoods of midbrain or peri-mesencephalic lesions to be the cause, according to the nerve pathway. Somehow, post-stroke ONP has rarely been stressed in previous reports, contrast to dominantly studied traumatic, neoplastic or aneurysmal ONPs. As well, most traditional Korean medicine (TKM) studies about ONP are devoted to microvascular 
or idiopathic factors, but post-stroke ONP is rarely reported ${ }^{4-6}$.

Post-stroke ONP patients are much commonly found and difficult-to-treat than previously reported. Kim et $\mathrm{al}^{7}$ reported high prevalence and bad prognosis of post-stroke paralytic strabismus including ONP. Current conventional treatments are composed of managing risk factors, prescribing antiplatelets, occluding the affected eye, applying Fresnel prism or injecting botulinum toxin 9 . They are practiced in many cases but seem difficult to obtain satisfactory therapeutic outcomes. Surgical treatments are expensive, but they have risks of over-correction or under-correction. TKM treatments would be a great choice because they are more effective, low-cost and less harmful. More studies are demanded to make therapeutic advantages of TKM evident. We treated three post-stroke ONP patients with TKM therapies. One patient had subarachnoid hemorrhage (SAH) with non-recovery for 35 days after the onset and two patients had midbrain infarction lesions, all with severe initial ptosis and ophthalmoplegia. All of them had considerably good improvements, so we are reporting on them.

\section{Case report}

\section{Case 1}

A woman with no significant past history, aged 61, a non-smoker who used to drink a bottle of beer every day, had lost her consciousness followed by a sudden, severe throbbing headache. Brain computed tomography (CT) and computed tomography angiography (CTA) showed an acute $\mathrm{SAH}$, rupture of right anterior choroidal aneurysm, and unruptured PcoA aneurysm (Fig. 1). Right PcoA aneurysm clipping had been immediately gone through. 17 days later, recovering alertness, complete ptosis and ophthalmoplegia at right side of eye was revealed. She was transferred to our clinic after 35 days from the onset. Neurological examination revealed completely limited extraocular movement except for abduction, complete ptosis, horizontal nystagmus at left side gaze, all at the right side of eye and eyelid. Additionally, left side tongue deviation and both upper extremity intention tremor was present. Some steroids and anti-histamines were prescribed for rashes all over the body. Discharge medication from former hospital consisted of Levetiracetam $500 \mathrm{mg}$ and Acetyl-L-Carnitine hydrochloride $590 \mathrm{mg}$, each to take twice a day. Electrocardiogram showed first degree arteriovenous block, but she had no related symptoms and vital signs were stable.

She was treated with a variety of herbal decoctions because of severe rash and fever, which was considered as drug allergy. Modified Buzhong Yiqi-tang, modified Yinqiao Baidusan, modified Shentong Zhuyu-tang, modified Wen Qing-yin, modified Banxia Baizhu Tianma-tang and modified Qinggan Mingmu-tang (Table 1), volume of $100 \mathrm{cc}$ each, three times per day, were used until ptosis and ophthalmoplegia had fully recovered. The acupuncture treatment was performed at Jingming (BL1), Zanzhu (BL2), Tongziliao (GB1), Chengqi (ST1), Sibai (ST2), Yin-tang (EX-HN3), Yuyao (EX-HN4), Taiyang (EX-HN5), Hegu(LI4), Taichong (LR3), Baihui (GV20), twice a day.

The effect of the treatment was evaluated by palpebral fissure (PF; the vertical height between the eyelids $)^{8}$ and vertical and horizontal range of corneal light reflex from center to each margin of eyelids. At 51th day of admission, the chief symptom had vanished. PF improved from 0/9 
$\mathrm{mm}$ to $9 / 9 \mathrm{~mm}$. Range of corneal light reflex has also changed, elevation from $0 / 5 \mathrm{~mm}$ to $5 / 5 \mathrm{~mm}$, depression from $1 / 4 \mathrm{~mm}$ to $4 / 4 \mathrm{~mm}$, and adduction from $-1.5 / 12 \mathrm{~mm}$ to $12 / 12 \mathrm{~mm}$ (Fig. 2, 3).

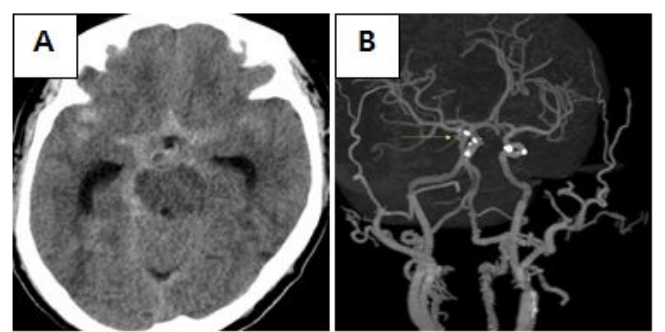

Fig. 1. Images of brain computed tomography, case 1.

They were scanned on the onset of SAH. It shows an acute $\mathrm{SAH}$ (A) and aneurysm at right $\mathrm{PcoA}, 3.16 \mathrm{~mm}$ in size (B). The yellow arrow points at the aneurysm.

Table 1. Herbal Decoctions, Administration Periods and Herbs Prescribed to Case 1, 2 and 3

\begin{tabular}{|c|c|c|c|}
\hline & $\begin{array}{c}\text { Herbal } \\
\text { decoction }\end{array}$ & $\begin{array}{l}\text { Administration } \\
\text { periods }\end{array}$ & Name and amount of herbs, per a dose of decoction \\
\hline & $\begin{array}{l}\text { Modified } \\
\text { Buzhong } \\
\text { Yiqi-tang }\end{array}$ & Day $1-3$ & 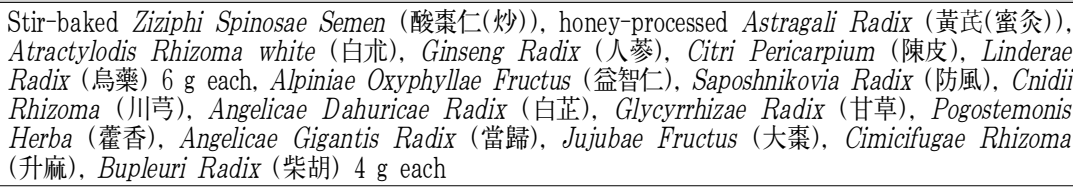 \\
\hline & $\begin{array}{l}\text { Modified } \\
\text { Yinqiao } \\
\text { Baidusan }\end{array}$ & Day 4-11 & 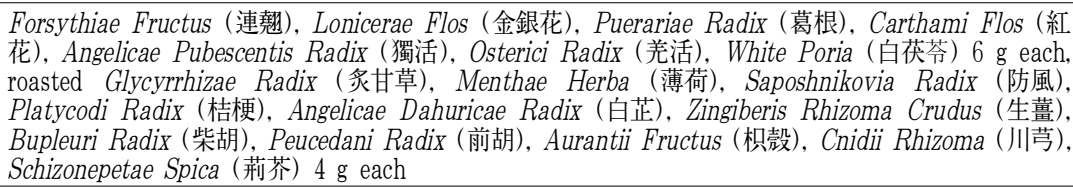 \\
\hline & $\begin{array}{l}\text { Modified } \\
\text { Shentong } \\
\text { Zhuyu-tang }\end{array}$ & $\begin{array}{l}\text { Day } 12-14 \\
\text { Day } 24-30\end{array}$ & $\begin{array}{l}\text { Forsythiae Fructus (連趣), Lonicerae Flos (金銀花), Angelicae gigantis Radix (當歸), Persicae } \\
\text { Semen (桃仁), Carthami Flos (紅花) } 8 \mathrm{~g} \text { each, Puerariae Radix (葛根), Achyranthis Bidentata } \\
\text { Radix (葛根), Myrrha (沒藥), Cyperi Rhizoma (香附子), roasted Glycyrrhizae Radix (多甘草) } 6 \\
\text { g each, Osterici Radix (芜活), Gentianae Macrophyllae Radix (秦艽), stir-baked Trogopterorum } \\
\text { Faeces (五靈脂(炒)), Angelicae Pubescentis Radix (獨活), Saposhnikovia Radix (防風), Angelicae } \\
\text { Dahuricae Radix (白芷), Cnidii Rhizoma (川芎) } 4 \mathrm{~g} \text { each. }\end{array}$ \\
\hline Case 1 & $\begin{array}{l}\text { Modified } \\
\text { Wen } \\
\text { Qing-yin }\end{array}$ & Day $15-23$ & 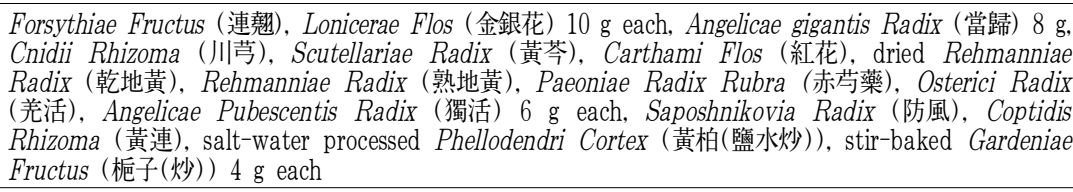 \\
\hline & $\begin{array}{c}\text { Modified } \\
\text { Banxia } \\
\text { Baizhu } \\
\text { Tianma-tang }\end{array}$ & $\begin{array}{l}\text { Day } 31-37 \\
\text { Day } 44-54\end{array}$ & 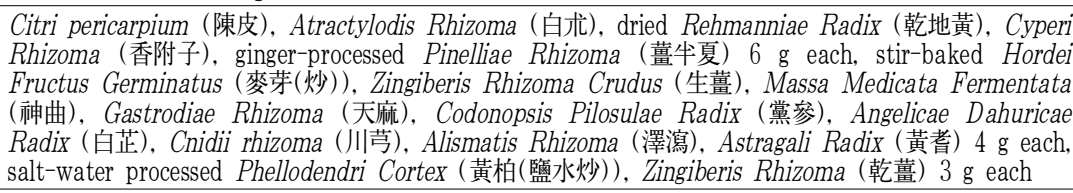 \\
\hline & $\begin{array}{c}\text { Modified } \\
\text { Qinggan } \\
\text { Mingmu-tang }\end{array}$ & Day $38-43$ & 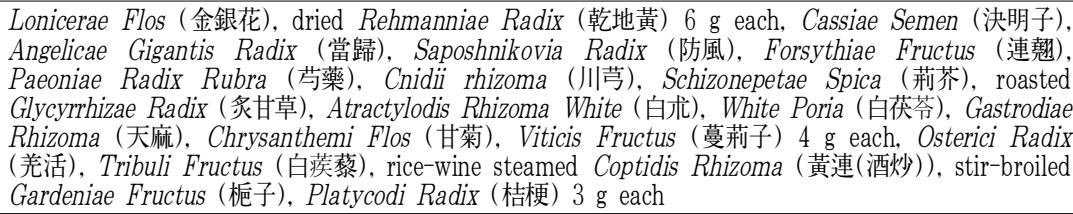 \\
\hline
\end{tabular}


Post-Stroke Oculomotor Nerve Palsy Treated by Traditional Korean Medicine: Three Case Reports

\begin{tabular}{|c|c|c|c|}
\hline Case 2 & $\begin{array}{l}\text { Modified } \\
\text { Buzhong } \\
\text { Yiqi-tang }\end{array}$ & Day 1-20 & 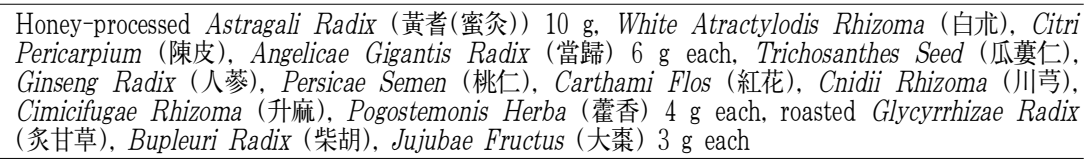 \\
\hline \multirow[t]{2}{*}{ Case 3} & $\begin{array}{l}\text { Modified } \\
\text { Buzhong } \\
\text { Yiqi-tang }\end{array}$ & $\begin{array}{l}\text { Day } 1-45 \\
\text { Day } 56-93\end{array}$ & 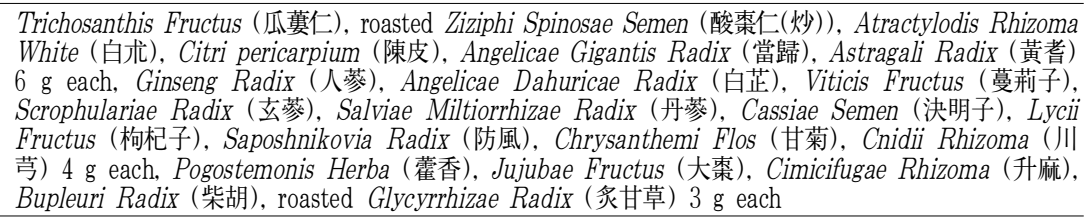 \\
\hline & $\begin{array}{c}\text { Modified } \\
\text { Tongqiao } \\
\text { Huoxue-tang }\end{array}$ & Day $46-55$ & 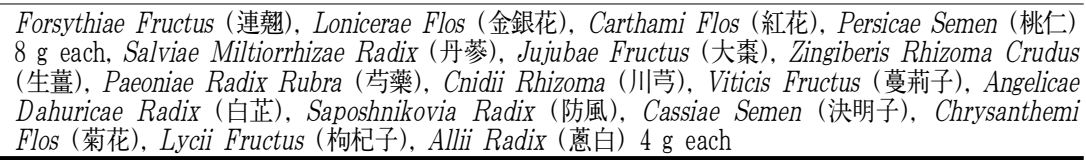 \\
\hline
\end{tabular}

Patients were prescribed with 2 doses, $300 \mathrm{ml}$ of herbal decoctions per day, divided into three packs.
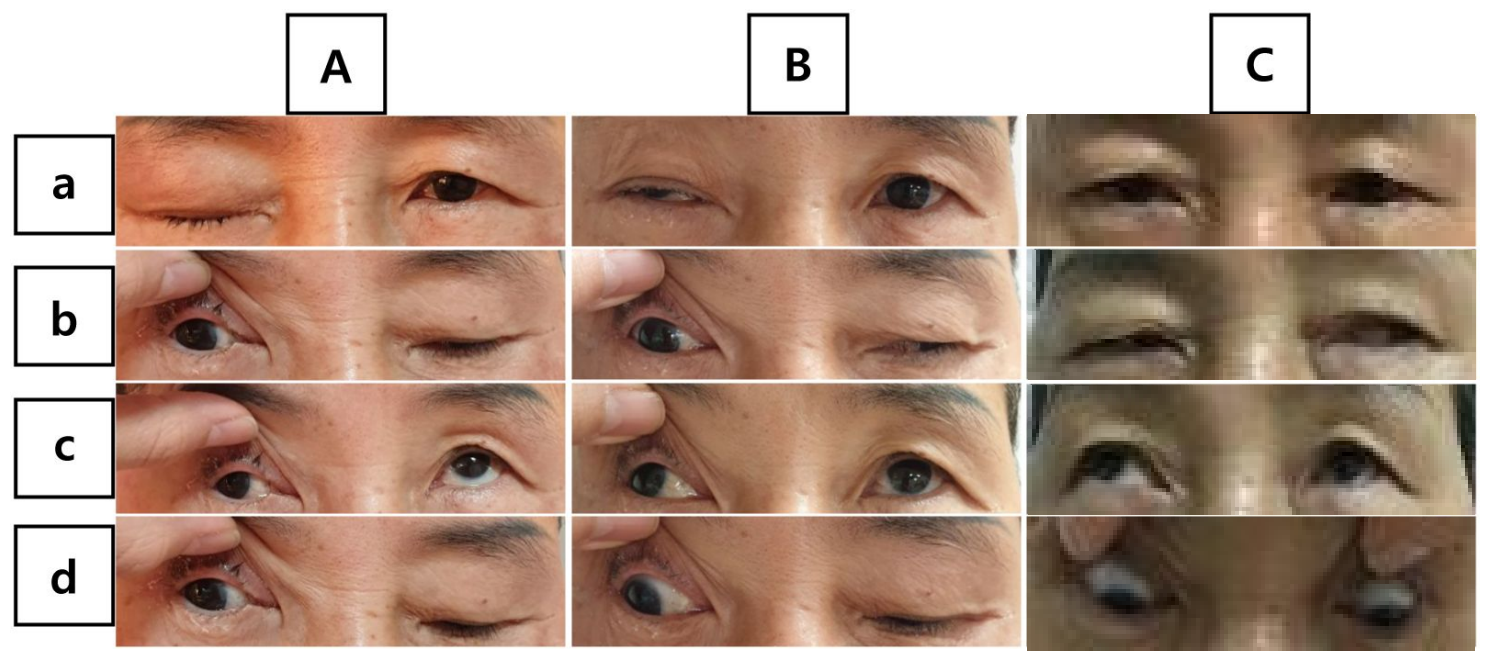

Fig. 2. Therapeutic progress of case 1.

Forward gaze (a), adduction (b), supraduction (c), infraduction (d), day of admission (A), 17th day of admission (B), 51th day of admission (C).

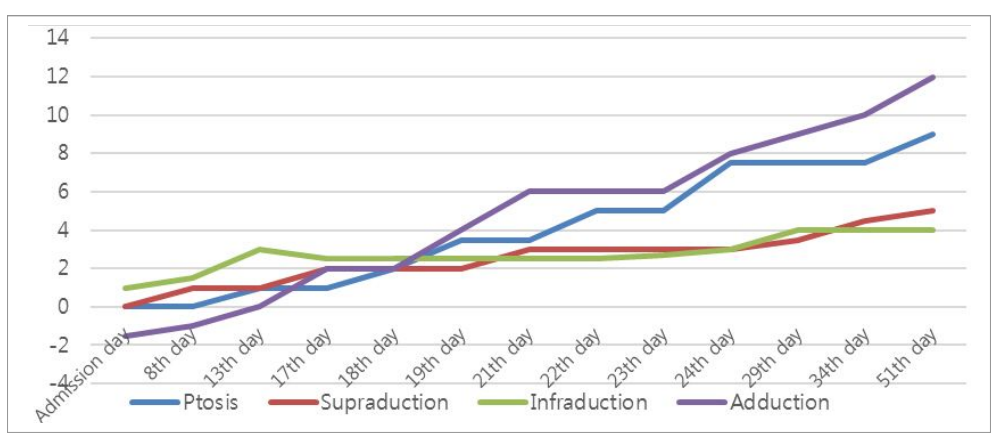

Fig. 3. The change of palpebral fissure, supraduction, infraduction, adduction range of right eyeball, case 1. 


\section{Case 2}

There was a 55-year old woman, with past medical history of hypertension and diabetes mellitus. She suddenly felt discomfort at keeping her right eye open, after suffering from dizziness for 2 days. As the ptosis progressed completely, she visited emergency room 3 hours later from the onset, and brain magnetic resonance imaging (MRI) scan revealed infarction at right midbrain (Fig. 4). Partial limitations of ipsilateral eye elevation, adduction and mild dysarthria were also found out by neurological examination. She had immediately received $100 \mathrm{mg}$ of Aspirin every morning. On admission to our clinic, after a week from the onset, dizziness and ophthalmoplegia had disappeared but complete ptosis was still present. We prescribed her modified Buzhong Yiqi-tang (Table 1) for 20 days from admission to discharge. The acupuncture treatment was also performed at BL1, BL2, GB1, ST1, ST2,
EX-HN3, EX-HN4, EX-HN5, LI4, LR3 and GV20 twice a day. PF was used as rating scale, and it has improved from $0.5 / 8 \mathrm{~mm}$ to $2.5 / 8 \mathrm{~mm}$, by the time of discharge (20th day of admission) (Fig. 5, 6).

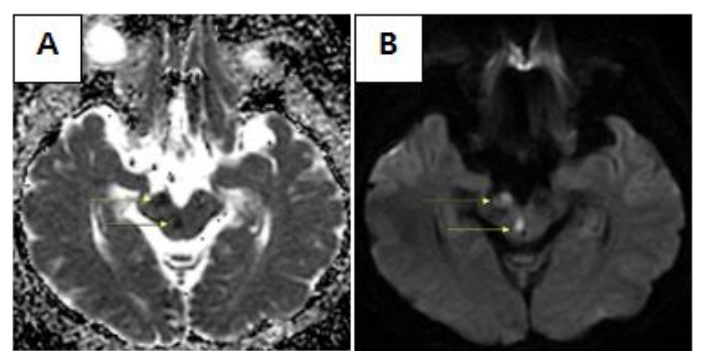

Fig. 4. Images of brain magnetic resonance imaging, case 2.

They were scanned on the onset of brain infarction. ADC (apparent diffusion coefficient) (A), DWI (diffusion weighted imaging) (B). Yellow arrows point at the ischemic lesions of midbrain.

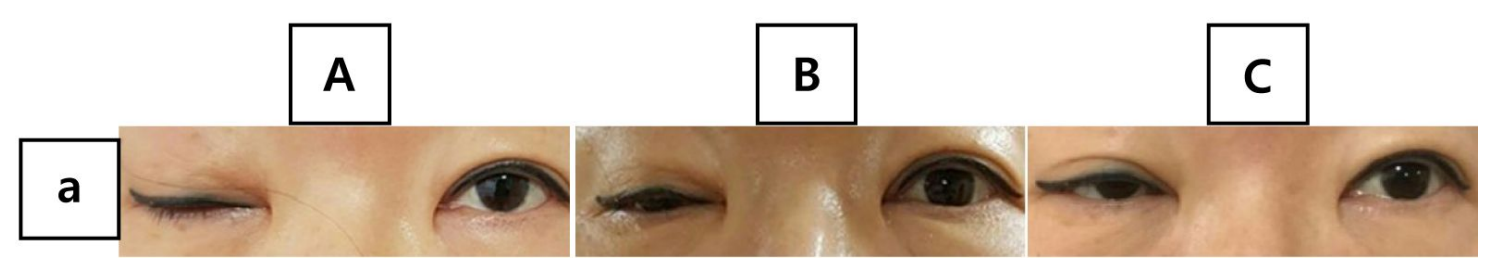

Fig. 5. Therapeutic progress of case 2.

Day of admission (A), 4th day of admission (B), 20th day of admission (C), and PF (a)

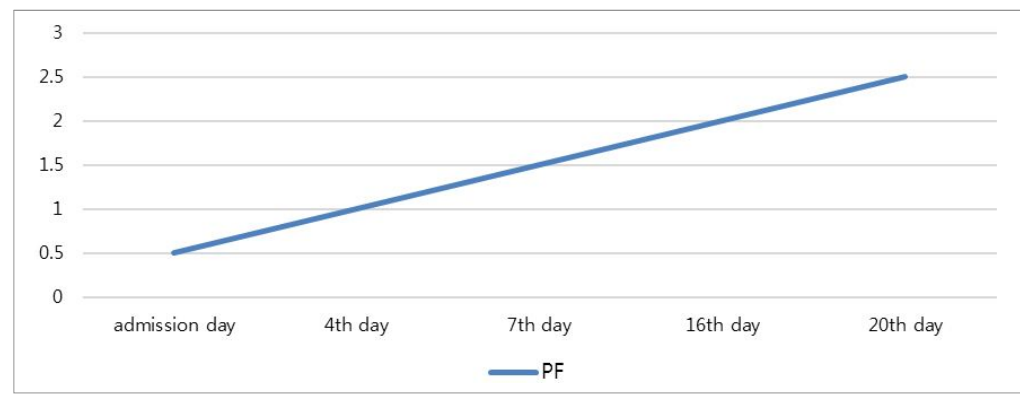

Fig. 6. The change of palpebral fissure, case 2. 


\section{Case 3}

There was a 66-year old man, diagnosed with hyperlipidemia a year ago, who had been drinking one to three bottles of rice wine every day, for twenty-years. He fell asleep at pm 8:30, drunk as usual. Next morning, he woke up feeling weakness on his both legs. Stumbling to bathroom, suddenly lost consciousness so he was transferred to emergency room right away. The MRI scan showed multiple posterior infarction at both midbrain, left thalamus, right medulla, both posterior inferior cerebellar artery (PICA) territory and left superior cerebellar artery (SCA) territory (Fig. 7). CTA showed top of basilar artery (BA) occlusion, so the intra-arterial thrombolysis was conducted. Recovering his consciousness after few hours, he got his strength back but also recognized both of his droopy eyes. Atrial fibrillation was also revealed by transthoracic echocardiography, so doctors prescribed him Apixaban $2.5 \mathrm{mg}$ twice daily. He was admitted to our clinic after a week from the onset. Neurological examination showed bilateral ptosis, loss of both light reflex, partial impairment of bilateral eye adduction, complete impairment of bilateral eye elevation and depression, pain in both eyeballs and left arm ataxia. He was prescribed with $100 \mathrm{cc}$ of modified Buzhong Yiqi-tang for most part of his 3-month hospital stay, and modified Tongqiao Huoxue-tang for 10 days, $100 \mathrm{ml}$ each, three times a day (Table 1). Medications containing anticoagulants, hypolipidemic agents were also continued. Acupuncture was also practiced two times a day, at BL1, BL2, GB1, ST1, ST2, EX-HN3, EX-HN4, EX-HN5, LI4, LR3 and GV20. PF and range of corneal light reflex from center to each margin of eyelids were also used as rating scale ${ }^{8}$. PF increased from $0.5 / 2 \mathrm{~mm}$ to $1 / 3 \mathrm{~mm}$, elevation range of corneal light reflex from $0.5 / 1 \mathrm{~mm}$ to $3 / 4 \mathrm{~mm}$, depression range of corneal light reflex from $1 / 1.5 \mathrm{~mm}$ to $3.5 / 5 \mathrm{~mm}$ and adduction range from $0 / 0 \mathrm{~mm}$ to $3 / 5.5 \mathrm{~mm}$ (Fig. 8, 9).

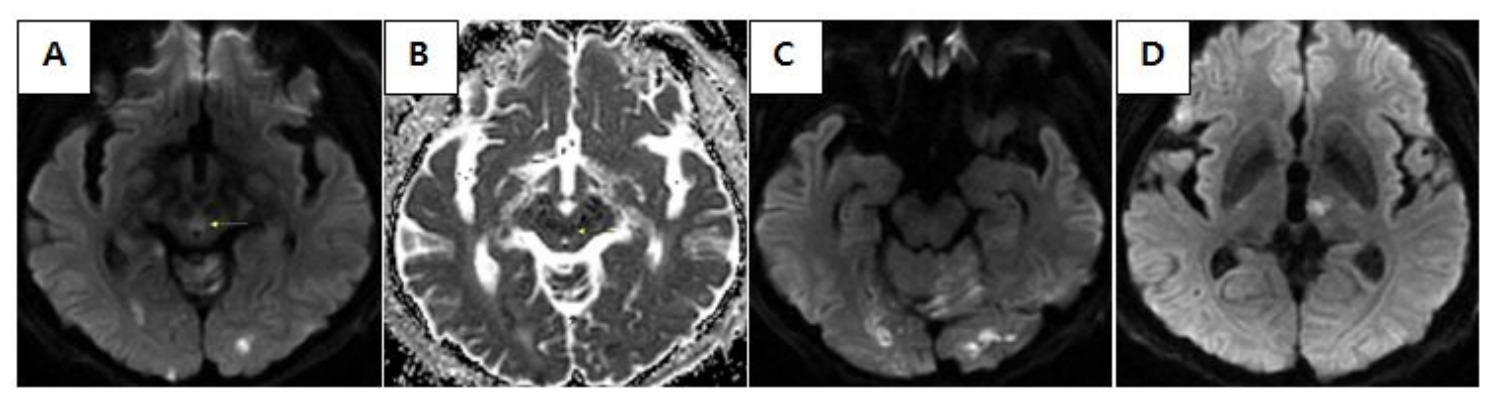

Fig. 7. Images of brain magnetic resonance imaging, case 3.

They were scanned on the onset of infarction. DWI (A), ADC (B) showing acute infarction of both midbrain. DWI showing acute infarction of both ICA territory, left SCA territory, left PICA territory (C) and left thalamus (D). Yellow arrows point at the lesions of midbrain. 


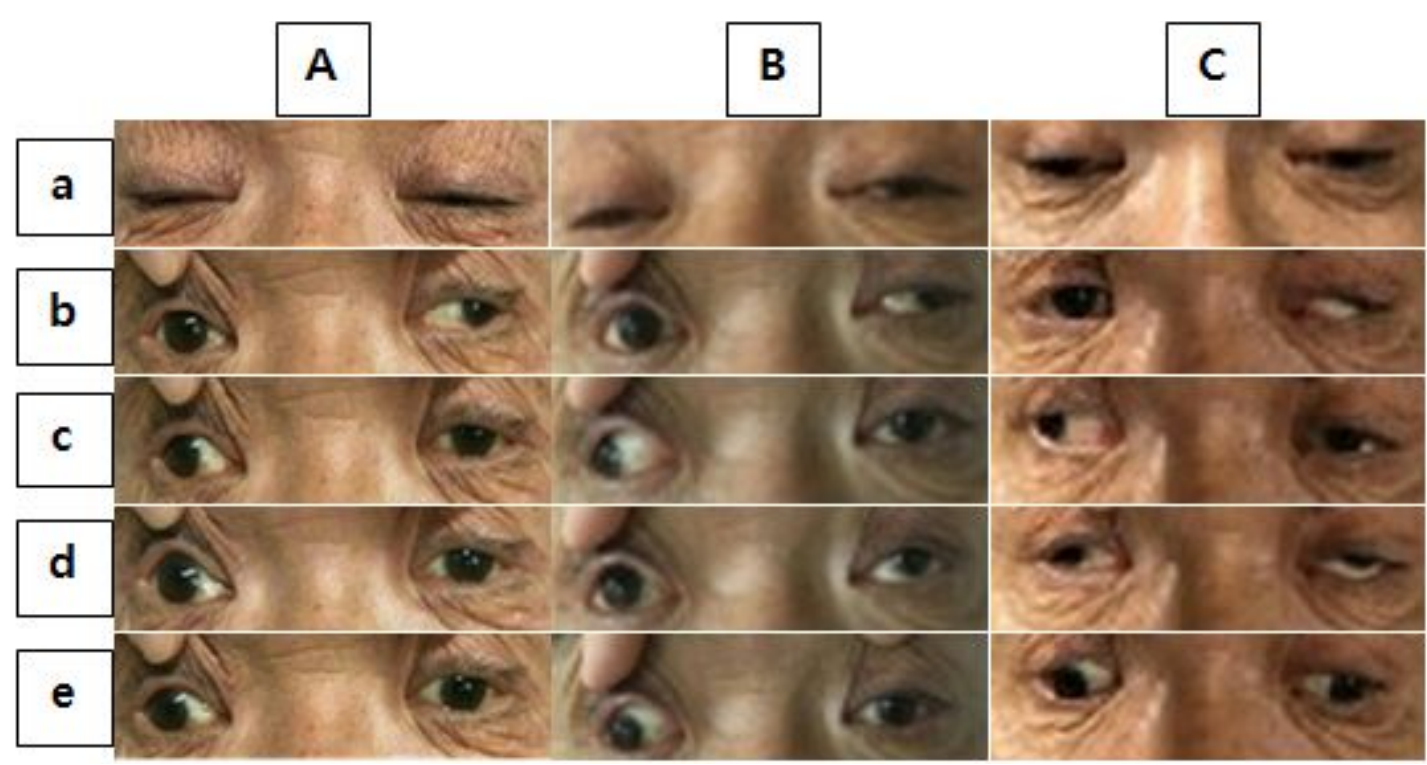

Fig. 8. Therapeutic progress of case 3 .

Day of admission (A), 11th day of admission, 82th day of admission (C), forward gaze (a), left side gaze (b), right side gaze (c), supraduction (d), infraduction (e).

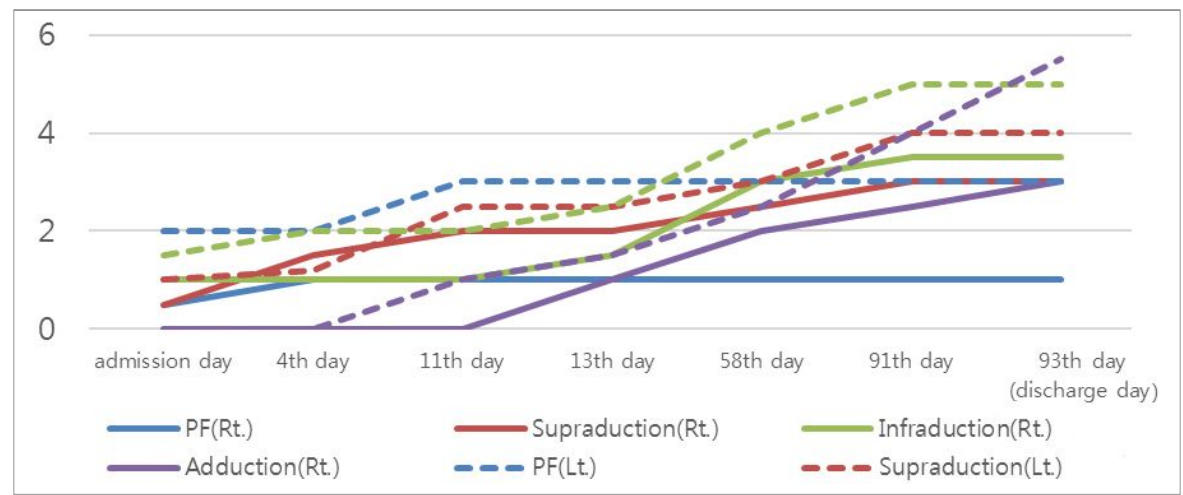

Fig. 9. The change of palpebral fissure, supraduction, infraduction, and adduction of both eyes, case 3 .

The data of right eye is shown as continuous line, and data of left eye is shown as dotted line.

\section{Discussion}

Western medical treatments of ONP are focused on managing risk factors and prescribing antiplatelets ${ }^{9}$. They are important but insufficient to shorten therapeutic period and make better recovery. So additional therapies to make direct effects are demanded. Blurring lens of glasses with surgical semi-opaque tape or applying eye patch to the affected side are frequently used to relieve discomfort caused by diplopia. Fresnel prism can also be applied to realign the visual axis. Due to 
changing degree of misalignment in the recovery phase, various degrees of prisms are frequently required $^{11}$. However, unilateral eye occlusion and prism therapies are just used to make adjustment to paretic condition, not to treat underlying ophthalmoplegia. Botulinum toxin injections to antagonist muscle of the affected eye are also used to resolve muscle contracture, but the effect only lasts for 3 to 6 months. Surgical treatment may be considered after follow up of 6 to 12 months ${ }^{11}$, because of its difficult process, risk of post-operative over-correction or under-correction ${ }^{10}$, and high risk of relapse ${ }^{11}$.

In TKM terms, ophthalmoplegia and diplopia can be explained as fengqian-pianshi (風旁偏視) or shiyi-weier (視一爲二). Ptosis can be explained as sangbao-xiachui (上胞下垂) or baochui (胞垂). The causes are categorized into stagnation of blood, deficiency of spleen, wet-phlegm obstruction, attack of wind or wind-heat, and wind of liver moving inside $^{12}$. We also considered brain infarction or hemorrhage to be treated, as it is the original cause of our three cases. Stroke is symmetrical to zhongfeng（中風） in TKM. Fire-heat, wet-phelgm, qi deficiency, yin deficiency or blood stagnation are the possible causes ${ }^{13}$.

Many former studies have proposed herb decoction or acupuncture therapy to treat ONP. Jung et $\mathrm{al}^{4}$, Kim et $\mathrm{al}^{5}$, Jun et $\mathrm{al}^{6}$ and Kim et $\mathrm{al}^{14}$ suggested Buzhong Yiqi-tang as the therapy of ONP. All of them differentiated the symptoms as spleen-qi deficiency on the basis of the theory that eyelids are related to qi of spleen. Furthermore, as the cause of diplopia is regarded as liver-wind, herbs that eliminate liver-wind by nourishing liver-blood are frequently used ${ }^{12}$. Acupuncture is a method of moving vital Qi through the meridian system, by stimulating acupoints on the base of TKM categorization $^{15}$. Additional studies have asserted the effectiveness of stimulating acupoints around the eye, Xingnao Kaiqiao technique (醒腦開竅法), scalp acupuncture, multi-needle shallow acupuncture, pharmacopuncture, electro acupuncture and fire-needling acupuncture. Especially, many studies have reported that stimulating acupoints around the eye would achieve good effect for treating the symptoms of $\mathrm{ONP}^{16}$. According to analysis of 33 studies about acupuncture treatment for $\mathrm{ONP}^{16}$, acupoints of BL1, BL2, ST2, TE23, Ex-HN5, LI4, GB14, ST36, GB20, and GB1 turned up to be the most frequently used acupoints. Attempt of more invasive acupuncture therapy, by direct stimulation of extraocular muscles, has also been done and has shown good improvement ${ }^{17}$.

The first patient's ipsilateral ophthalmoplegia, including SR, implies fascicular lesion because the oculomotor nucleus has contralateral innervation to SR. Although PcoA aneurysm is the highest risk of isolated ONP among all the other aneurysms, it's not relevant in this case. The aneurysm has to be at least $4 \mathrm{~mm}$ to injure the nerve $^{18}$, but the patient's one was only $3 \mathrm{~mm}$ in diameter. Also, ophthalmoplegia and ptosis lasted for 3 months after the elimination of the aneurysm. The patient's symptoms lasted too long to be regarded as transient ischemic attack, and no ischemic lesions at the third nervous pathway were found by MRI scan. While there are several other causes that might cause the nerve damage after $\mathrm{SAH}$, such as vasospasm, intracranial pressure elevation, or subarachnoid clot $^{19}$, we suspected the blood clot in subarachnoid cistern to have induced the neuropathy. Severe hemorrhage at subarachnoid space, especially at right side of peri-mesencephalic 
cistern, was revealed by CT. In TKM, she was identified as blood-stasis type and attack of wind type due to severe, persisting ONP accompanied with nighttime aggravating rash. So, the medications were focused on eliminating stagnation of blood by diffusing and circulating blood. The original decoctions, containing forsythiae fructus (連䞨) and lonicerae flos (金銀花), were focused on symptoms of drug fever. Carthami flos (紅花), cnidii rhizoma (川芎), angelicae pubescentis radix (獨活) to remove blood stagnation, and osterici radix (姜活), saposhnikovia radix (防風) to eliminate wind, were added to almost every decoctions she took. Her ONP symptoms resolved completely at 85th day of the onset and 51 th day of the admission to our hospital. Considering that it was a complete palsy and was too severe that there was no improvement at all before the Korean medical treatment was done, it is obvious that the treatment we performed was effective.

The second patient was diagnosed with fascicular-0NP, because her ptosis was ipsilateral. Usually, ptosis caused by midbrain lesions occur bilaterally because of the damage of central caudal nucleus, which innervates LP bilaterally ${ }^{2,20}$. In some exceptional cases, unilateral ptosis occurs with midbrain lesions, which the cause is considered as fascicular lesion of oculomotor nerve ${ }^{21}$. In this case, lesions were shown at midbrain and cerebral peduncle, where the fascicles are located. She was identified as spleen-qi deficiency, so modified Buzhong Yiqi-tang was prescribed to supplement qi of spleen. Persicae semen (桃仁), carthami flos (紅花), cnidii rhizoma (川芎) was also added to remove blood stagnation, considering the ischemic lesion.

The third patient had almost complete ptosis and ophthalmoplegia except for LR, at both eyes, which can explain lesions at both oculomotor nucleus. He was also diagnosed as spleen-qi deficiency, according to his swollen tongue and weak pulse, so was medicated with modified Buzhong Yiqi-tang. Trichosanthis fructus (瓜萣仁) and cnidii rhizoma (川芎) were added to eliminate stagnation of Qi, phlegm and blood. Considering his irritating eyeballs, cassia semen (決明子), lycii fructus (枸杞子), chrysanthemi flos (甘菊) were supplemented, which cool liver fire and supply liver blood, resulting in alleviation of the eye function. As obstructions of cerebral vessels were severe, the improvements were slow compared to the first and second case. However, the ophthalmoplegia showed fairly good progress. Owing to diplopia, he couldn't take even one step on the admission. But by the time of discharge, he was able to go anywhere he wanted assisted by walker and walk more than 30 steps by himself. He visited OPD continuously, and recovered both extraocular functions fully, 6 months after discharge.

In our study, the effects of TKM treatments including acupuncture and herbal decoctions on ONP were confirmed. Around-eye acupoints stimulation, which is reported to be effective and frequently practiced $^{16}$, was common treatment for our three patients. It is thought to have made relaxation of extraocular muscle fascia and fibers, activated blood and lymph circulation ${ }^{22}$, resulting in recovery of ophthalmoplegia and ptosis. Also, all three patients were prescribed with Buzhong Yiqi-tang, which had been proved to have neuro-protective effect by antioxidation and anti-inflammatory effect ${ }^{23}$. First patient's hemorrhagic lesion in subarachnoid cistern may cause neural damage or vasospasm-induced secondary ischemia by releasing oxyhemoglobin or 
endothelin ${ }^{2}$. Second and third patient had ischemic lesions, so lack of oxygen and glucose may also cause neural damage and inflammation ${ }^{2}$. The herbal treatments are thought to have alleviated the neurological symptoms by managing with neural damage and inflammation.

In conclusion, by measuring of $\mathrm{PF}$ and vertical \& horizontal range of corneal light reflex from center to each margin, all three patients applied with TKM treatments had shown great improvement at ONP symptoms. It also has affected the quality of daily life, as dizziness and gait disturbance due to diplopia had resolved. They would be adequate choices to treat ONP according to its low side effect, low cost and more effective techniques compared to managing risk factors, antiplatelets, conservative treatments, botulinum toxin or operations. However, lack of studies about post-stroke ONP made it difficult to analyze exact therapeutic effect. As damage of central nervous system is usually long-lasting and leaves severe sequelae, more studies about prevalence, treatment rate, treatment period and therapeutic mechanisms of post-stroke ONP are required.

\section{References}

1. Fricke J, Neugebauer A. Surgical options for eye muscle surgery in third nerve palsy. Klin Monbl Augenheilkd 2009:226(10):801-5.

2. Korean Neurological Association. Neurology. 3rd edition. Seoul: panmun education; 2017, p. 168-70, 645-94.

3. Fang C, Leavitt JA, Hodge DO, Holmes JM, Mohney BG, Chen JJ. Incidence and Etiologies of Acquired Third Nerve Palsy Using a Population-Based Method. JAMA Ophthalmol
$2017 ; 135(1): 23-8$.

4. Jung YD, Kim JH, Song MS, Park YS, Heo YK, Kim YI, et al. Case Reports : The clinical study on 2 cases of Patients of Idiopathic Blepharoptosis. The Journal Of Korean Acupuncture \& Moxibustion Medicine Society 2004;21(6): $281-9$.

5. Kim MJ, Won SY, Cho HK, Yoo HR, Seol IC, Kim YS. A Case Report of Ptosis and Eye Movement Limitation Caused by Idiopathic Oculomotor Nerve Palsy. $J$ Int Korean Med 2019;40(3) :499-505.

6. Jun HJ, Hwang U, Kim JI, Lee HM, Nam SS, Kim YS. Case Reports : Case Report of Oculomotor palsy patient treated with Electroacupuncture. The Journal of Korean Acupuncture \& Moxibustion Medicine Society 2002;19(4):200-7.

7. Kim K, Noh SR, Kang MS, Jin KH. Clinical Course and Prognostic Factors of Acquired Third, Fourth, and Sixth Cranial Nerve Palsy in Korean Patients. Korean J Ophthalmol 2018; $32(3): 221-7$.

8. Park HH, Chun YS, Moon NJ, Kim JT, Park SJ, Lee JK. Change in eyelid parameters after orbital decompression in thyroid-associated orbitopathy. Eye (Lond) 2018:32(6):1036-41.

9. Galtrey CM, Schon F, Nitkunan A. Microvascular Non-Arteritic Ocular Motor Nerve Palsies-What We Know and How Should We Treat? Neuroophthalmology 2015:39(1):1-11.

10. Chougule P, Kekunnaya R. Surgical management of intermittent exotropia: do we have an answer for all? BMJ Open Ophthalmology 2019;4(1) :e000243.

11. Danchaivijitr C, Kennard C. Diplopia and eye movement disorders. J Neurol Neurosurg Psychiatry 2004;75(4):24-31. 
12. Noh SS. Ophthalmology \&Otolaryngology. 1st edition. Seoul: Iljungsa; 1999, p. 12, 107-08, 73-5, 212-21.

13. Department of Cardiology \& Neurology of Korean Mecine College. Korean medicine of Cardiology \& Neurology. 4th edition. Seoul: Koonja books; 2010, p. 404-15.

14. Kim SB, Jeong YK, Yang JY, Mun SK, Jung WS, Kwon SW, et al. A Case Report of a Patient with Ptosis and Ataxia Diagnosed as Claude's Syndrome Who Was Treated with Korean Medicine. J Int Korean Med 2017; 38(2) :93-102.

15. Inanc BB. A New Theory on the Evaluation of Traditional Chinese Acupuncture Mechanisms from the Latest Medical Scientific Point of View. Acupunct Electrother Res 2015;40(3) :189-204.

16. Ku YH, Kang JH, Kong HJ, Ryu HY, Lee H. A Systematic Review of Acupuncture for Oculomotor Nerve Palsy. Journal of Acupuncture Research 2019:36(2):59-71.

17. Kim NK. One Case of traffic accident induced paralytic strabismus (oculomotor nerve palsy) which was treated with electroacupuncture at oculomotor muscles. The Journal of Korean Oriental Medical Ophthalmology \& Otolaryngology
\& Dermatology 2008;21(1):133-8.

18. Vaphiades MS, Roberson GH. Imaging of Oculomotor (Third) Cranial Nerve Palsy. Neurol Clin 2017:35(1):101-13.

19. van Gijn J, Rinkel GJ. Subarachnoid haemorrhage: diagnosis, causes and management. Brain 2001; 124(Pt 2) :249-78.

20. Martin TJ, Corbett JJ, Babikian PV, Crawford SC, Currier RD. Bilateral ptosis due to mesencephalic lesions with relative preservation of ocular motility. J Neuroophthalmol 1996; $16(4): 258-63$.

21. Hriso E, Masdeu JC, Miller A. Monocular elevation weakness and ptosis: an oculomotor fascicular syndrome? J Clin Neuroophthalmol 1991:11(2):111-3

22. Lee HM, Kang SK, Kim CH, Kim YS. A Literuture Study on the Effect of Jung-an Acupuncture Meridian Point and Needling Method. The $J$ of Korean Acupuncture \& Moxibustion Society 2008:25(1):179-85.

23. Hwang GS, Kim HW, Choi CH, Jeong HW. Effects of BojungIkkiTang-Gamybang on Protective of Cell Death and Anti-Oxidative in C6 Glioma Cell. Korean J Oriental Physiology \& Pathology 2010;24(3) :401-9. 